\title{
Towards the production of microalgae biofuels: the effect of the culture medium on lipid deposition
}

\author{
Diego J. Cuellar García, Yeily A. Rangel-Basto, Andres F. Barajas-Solano, \\ Yaneth A. Muñoz-Peñalosa *, Nestor A. URBina-SUAREZ \\ Universidad Francisco de Paula Santander, Cúcuta, Norte de Santander, Colombia
}

\begin{abstract}
Microalgae have been studied in recent years for various reasons, one among them being their potential in the production of biofuels. Biofuels are considered as a renewable source that does not compete with the food industry, and their production results in a reduced environmental footprint. The objective of the present study was to evaluate the different culture conditions that influence the productivity of the microalgae Chlorella vulgaris and Scenedesmus obliquus as a potential source for the production of biodiesel. Bold, Bristol, and modified Algal Assay Procedure (AAP) culture media were evaluated to determine which of them can provide the best conditions that favor biomass production and lipid deposition. The results indicated that $S$. obliquus cultivated in Bold medium exhibited a higher production of biomass after 30 days $(1.730 \mathrm{~g} / \mathrm{l})$, while $C$. vulgaris showed a higher production in the modified AAP medium $(1.880 \mathrm{~g} / \mathrm{l})$. Although the cultures grown in the AAP medium showed a more significant percentage of biomass comprising lipids than those in the other two media, between the two microalgae, the highest final lipid production was obtained by growing S. obliquus in Bold medium (0.685 g/l, 39.60\% of biomass). N, P, Fe, and Mo were the elements added to the growth media, and depending on their concentration in the media, there were differences in the production of lipids. Thus, it can be concluded that S. obliquus cultivated in Bold medium has the highest potential in the production of lipids for biodiesel, but it is necessary to further optimize the cultivation of biomass to obtain a greater quantity of lipids, while interfering as little as possible in its synthesis capacity.
\end{abstract}

Key words: biomass production, biodiesel, algae production, Chlorella vulgaris, Scenedesmus obliquus

\section{Introduction}

The use of microalgae to obtain biofuels is based on the fact that under certain controlled growth conditions, it is possible to induce the production and accumulation of lipid compounds (Mandal and Mallik, 2009; Milano et al., 2016) that can be further transformed to obtain biofuels. As organisms that can perform photosynthesis with a high efficiency and reproduce in a short time with relatively few nutrients (Carvalho et al., 2012), microalgae possess the advantage of growing rapidly with high productivity and producing biofuels without the need of long stretches of land as required by plant sources such as corn, soy, palm oil, or sugarcane (Bohnenberger and Crossetti, 2014; Mandotra et al., 2016). In addition, their ability to fix $\mathrm{CO}_{2}$ contributes to the reduction of the environmental footprint generated by fossil fuels, which makes these algae an eco-friendly alternative.

On the other hand, forcing lipid accumulation in the algae will lead to a substantial reduction in the final concentration of biomass; thus, the conditions promoting a high accumulation of lipid compounds are antagonistic (Dragone et al., 2011). Generally, the culture media used for the production of algae (either at the laboratory or at the industrial scale) are designed with the sole aim of improving the production of specific metabolites. So to achieve a high accumulation of lipids, it is necessary to modify (increase or decrease) the concentration of one or several nutrients (Fazeli Danesh et al., 2018; Shin et al., 2018). Moreover, the biological diversity of microalgae leads to a wide variation between species and

\footnotetext{
* Corresponding author: Universidad Francisco de Paula Santander, Cúcuta, Norte de Santander, Columbia; e-mail: yanethamparomp@ufps.edu.co
} 
strains in the yield of lipids (Andersen et al., 2005); therefore, it is necessary to know certain aspects of each group of microalgae such as their biology, nutritional requirements, and growth conditions (Mandall and Mallick, 2009; Milano et al., 2016). Thus, the primary objective of the present investigation was to evaluate the effect of different culture media on lipid deposition in Chlorella vulgaris and Scenedesmus obliquus as sources for biodiesel production.

\section{Materials and methods}

\section{Microorganisms and culture conditions}

The algal species $C$. vulgaris and $S$. obliquus were purchased from NUTRÉ S.A.S (Colombia). They were cultured in Bold Basal Medium (Andersen, 2005) under a light intensity of $200 \mu \mathrm{molm}^{-2} \cdot \mathrm{s}^{-1}$ with $12: 12$ light: dark cycle at $28 \pm 2{ }^{\circ} \mathrm{C}$.

\section{Culture media}

The culture media used for the evaluation of lipid production by $C$. vulgaris and $S$. obliquus were Bold Basal (Andersen et al., 2005), Bristol (Andersen et al., 2005), and Algal Assay Procedure (AAP) (ASTM, 2012). These media were selected as they have been widely used in different studies, with the last one being an emulator of environmental conditions (Table 1).

\section{Analytical methods}

Biomass concentration (dry weight basis) was monitored every 5 days using the method described by Moheimani et al. (2013). Briefly, $15 \mathrm{ml}$ of culture was filtered using pre-weighted GF-C $47 \mathrm{~mm}$ filters (Pall Corporation). The filtered biomass was dried at $60^{\circ} \mathrm{C}$ overnight and stored in a desiccator until a constant weight was obtained.

The quantification of total lipids was carried out according to the protocol proposed by Folch and adapted by Moheimani and coworkers (2013). The concentrations of phosphate $\left(\mathrm{PO}_{4}\right)$ and nitrate $\left(\mathrm{NO}_{3}\right)$ were determined using Vanadomolybdophosphoric Acid Colorimetric Method (APHA, 2017) and Horiba LAQUAtwin Nitrate Sensor, respectively.

\section{Results}

According to the data presented in Figure 1, the culture medium that favored the highest production of bio
Table 1. Composition of the culture media evaluated

\begin{tabular}{|c|c|c|c|}
\hline \multirow{2}{*}{ Nutrients } & \multicolumn{3}{|c|}{ Culture media $[\mathrm{mg} / \mathrm{l}]$} \\
\hline & Bold Basal & Bristol & AAP \\
\hline $\mathrm{NaNO}_{3}$ & 250 & 125 & 25.5 \\
\hline $\mathrm{K}_{2} \mathrm{HPO}_{4}$ & 75 & 37.5 & - \\
\hline $\mathrm{KH}_{2} \mathrm{PO}_{4}$ & 175 & 87.5 & 1,04 \\
\hline $\mathrm{CaCl}_{2} \cdot \mathrm{H}_{2} \mathrm{O}$ & 25 & 12.5 & 4.41 \\
\hline $\mathrm{NaCl}$ & 25 & 12.5 & - \\
\hline $\mathrm{MgSO}_{4} \cdot 7 \mathrm{H}_{2} \mathrm{O}$ & 75 & 37.5 & 14.7 \\
\hline $\mathrm{MgCl}_{2} \cdot 6 \mathrm{H}_{2} \mathrm{O}$ & - & - & 12.16 \\
\hline $\mathrm{NaHCO}_{3}$ & - & - & 0 \\
\hline EDTA & 50 & 25 & 3 \\
\hline $\mathrm{KOH}$ & 31 & 15.5 & - \\
\hline $\mathrm{H}_{3} \mathrm{BO}_{3}$ & 11.42 & 5.71 & 1.9 \\
\hline $\mathrm{MnCl}_{2} \cdot 4 \mathrm{H}_{2} \mathrm{O}$ & 1.44 & 0.72 & 42 \\
\hline $\mathrm{ZnSO}_{4} \cdot 7 \mathrm{H}_{2} \mathrm{O}$ & 8.82 & 4.41 & - \\
\hline $\mathrm{MoO}_{3}$ & 0.71 & 0,36 & - \\
\hline $\mathrm{CuSO}_{4} \cdot 5 \mathrm{H}_{2} \mathrm{O}$ & 1.57 & 0.79 & - \\
\hline $\mathrm{Co}\left(\mathrm{NO}_{3}\right)_{2} \cdot 6 \mathrm{H}_{2} \mathrm{O}$ & 0.49 & 0.25 & - \\
\hline $\mathrm{FeSO}_{4} \cdot 7 \mathrm{H}_{2} \mathrm{O}$ & 4.98 & - & - \\
\hline $\mathrm{ZnCl}_{2}$ & - & - & 0.327 \\
\hline $\mathrm{Na}_{2} \mathrm{MoO}_{4} \cdot 2 \mathrm{H}_{2} \mathrm{O}$ & - & - & 0.726 \\
\hline $\mathrm{CuCl}_{2} \cdot 2 \mathrm{H}_{2} \mathrm{O}$ & - & - & 0.0012 \\
\hline $\mathrm{CoCl}_{2} \cdot 6 \mathrm{H}_{2} \mathrm{O}$ & - & - & 0.143 \\
\hline $\mathrm{FeCl}_{3} \cdot 6 \mathrm{H}_{2} \mathrm{O}$ & - & 2.42 & 1.6 \\
\hline $\mathrm{H}_{2} \mathrm{SO}_{4}(\mathrm{ml} / \mathrm{l})$ & 1 & 1 & - \\
\hline
\end{tabular}

mass of $S$. obliquus after 30 days of culture was Bold $(1.730 \mathrm{~g} / \mathrm{l})$, followed by Bristol $(1.455 \mathrm{~g} / \mathrm{l})$ and AAP $(0.895 \mathrm{~g} / 1)$. In the case of $C$. vulgaris, an opposite trend was observed: the highest biomass production was achieved using the AAP medium $(1.880 \mathrm{~g} / \mathrm{l})$, followed by Bristol (1.805 g/l) and Bold (1.750 g/l).

The productivity of the two algae was almost similar in the Bold and Bristol media, but significant differences were observed in the AAP medium $\left(0.063 \mathrm{~g} \cdot \mathrm{l}^{-1} \cdot \mathrm{d}^{-1}\right.$ for C. vulgaris and $0.029 \mathrm{~g} \cdot \mathrm{l}^{-1} \cdot \mathrm{d}^{-1}$ for S. obliquus). According to these results, $C$. vulgaris successfully adapted to all the three media evaluated, with the AAP medium being the one favoring the highest production of biomass and the highest productivity $\left(1.880 \mathrm{~g} / 1\right.$ and $0.063 \mathrm{~g} \cdot \mathrm{l}^{-1} \cdot \mathrm{d}^{-1}$, respectively) - Figure 2 . 


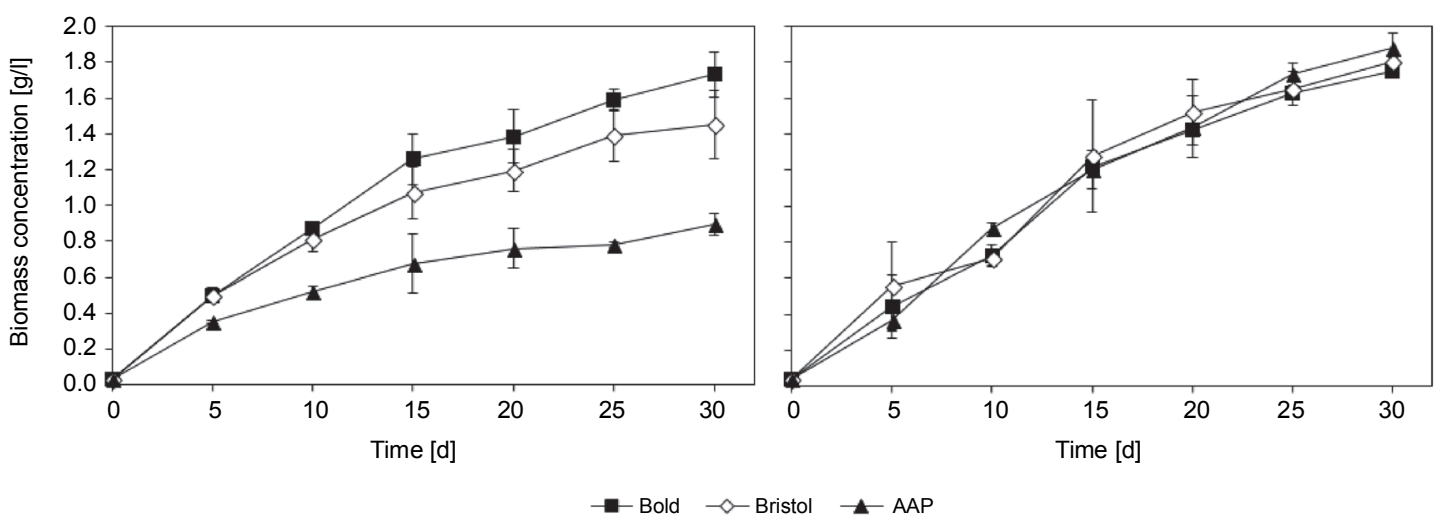

Fig. 1. Biomass concentration of Scenedesmus obliquus (left) and Chlorella vulgaris (right) in different culture media

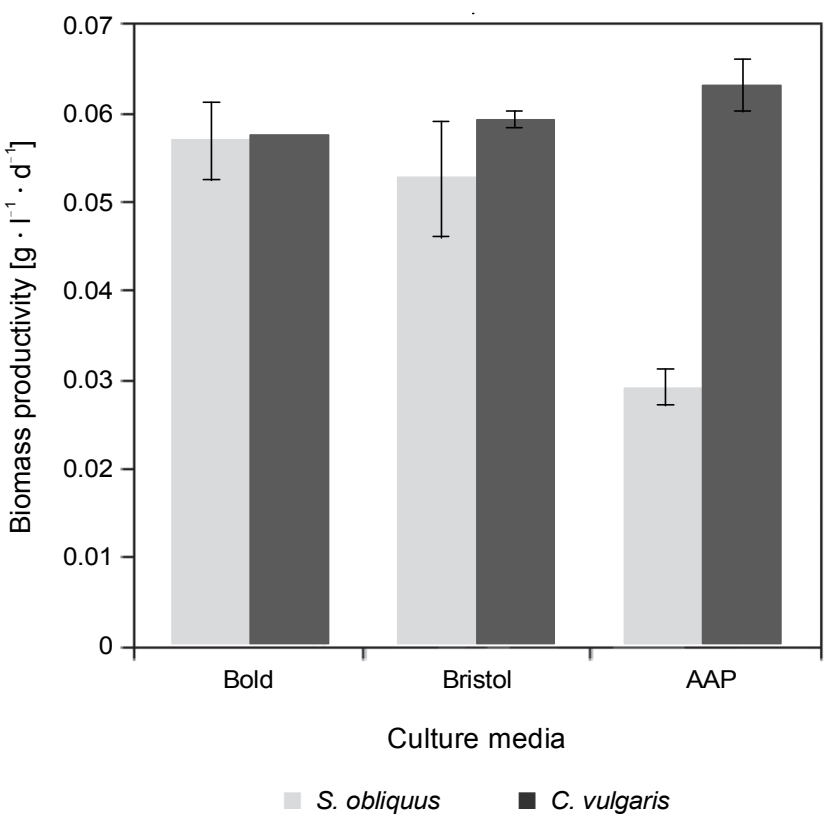

Fig. 2. Biomass productivity of Scenedesmus obliquus and Chlorella vulgaris evaluated in different culture media

According to the data presented in Figure 3, the consumption of both nitrate and phosphate was faster in the cultures of S. obliquus (Fig. 3). Nitrogen was exhausted within the first 10 days in all the cultures, with the consumption occurring first in the AAP medium, followed by Bristol and Bold. Unlike nitrate, phosphate was not completely utilized by any of the two algae in all the three media evaluated, which showed a repetitive behavior of consumption and a subsequent release to the medium (Fig. 3).

The highest percentage of lipids was produced by S. obliquus grown in the AAP medium $(52.51 \%, \mathrm{w} / \mathrm{w})$. However, the concentration of lipids $(0.470 \mathrm{~g} / \mathrm{l})$ was lower than that obtained in Bold and Bristol media $(0.685 \mathrm{~g} / 1$ and $0.570 \mathrm{~g} / 1$, respectively), even though the percentage of lipids obtained in these media was lower (39.60\% and 39.18\%, respectively) - Figur 4. In contrast, C. vulgaris produced similar percentages of lipids in Bold, Bristol, and AAP medium which were $14.29 \%$, $15.79 \%$, and $16.76 \%$, with final concentrations of $0.250 \mathrm{~g} / 1,0.285 \mathrm{~g} / \mathrm{l}$, and $0.315 \mathrm{~g} / \mathrm{l}$, respectively.

\section{Discussion}

Algal growth and the accumulation of specific metabolites (such as lipids, carbohydrates, proteins, and others) are stimulated to a different degree depending on the concentrations of different nutrients. Under the optimal culture conditions $(\mathrm{pH}$, temperature, and light regime), the biomass concentration is proportional to the uptake of the most limiting nutrients (Juneja et al., 2013). Rodríguez-Gil and coworkers (2014) obtained the highest cell concentration after 96 hours when cultivating Oophila sp. in the AAP medium, compared to Bold or Bristol. This result is similar to those observed in the present study for $C$. vulgaris, but not for $S$. obliquus, which, from the beginning, showed a difference in the assimilation of nutrients (Fig. 1). While both biomass productivity and lipid percentages were similar in all the media tested for $C$. vulgaris, low productivity of biomass was observed in the AAP medium for $S$. obliquus which was compensated by higher lipid content (Fig. 4). The opposite trend was observed in the Bold Basal Medium, where a lower percentage of lipids was compensated by higher productivity of biomass. Importantly, the percentages of lipids produced by $S$. obliquus in all the media 

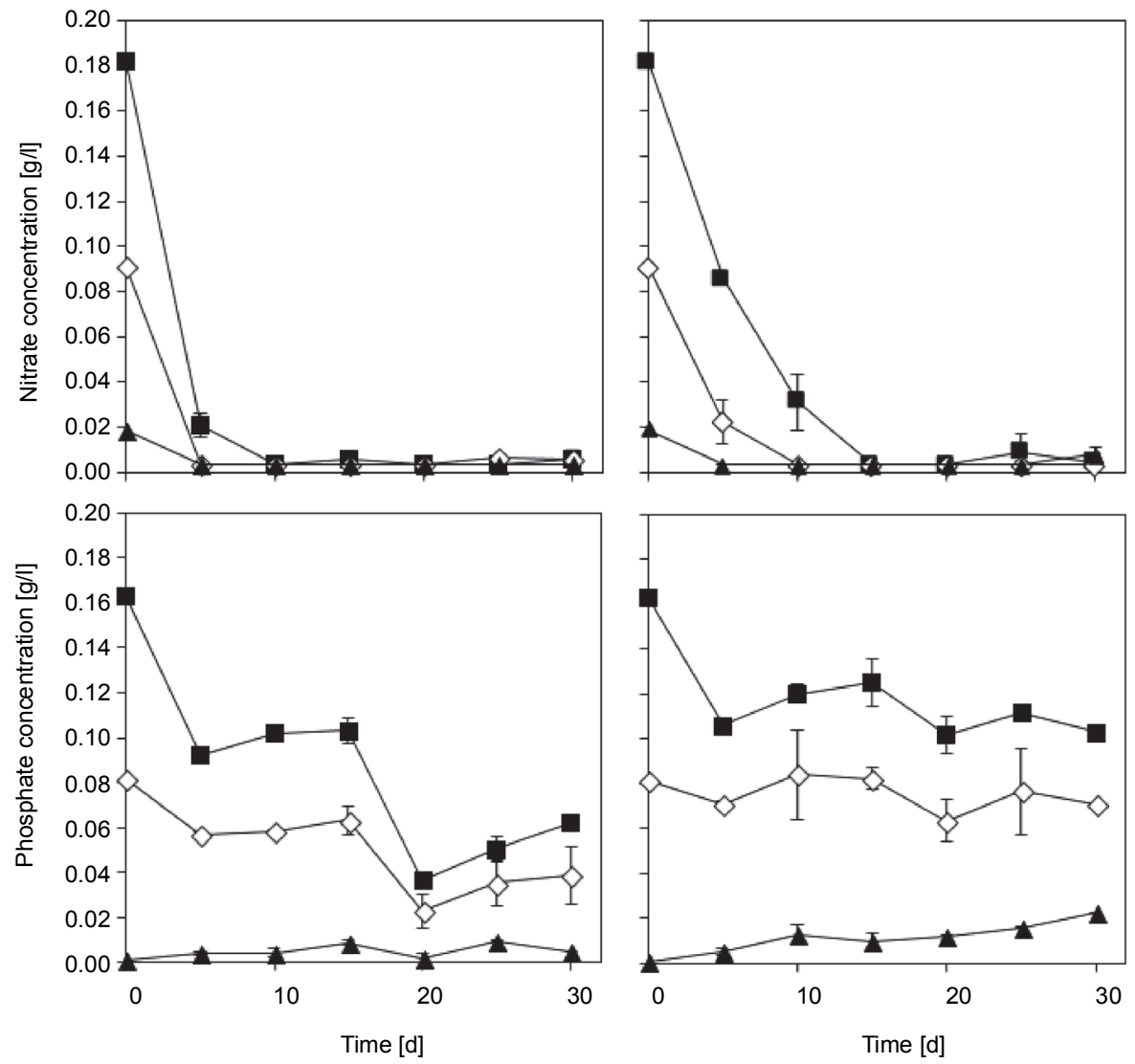

B Bold $\multimap$ Bristol $\leftarrow$ AAP

Fig. 3. Consumption of nitrate $\left(\mathrm{NO}_{3^{-}}\right)$and phosphate $\left(\mathrm{PO}_{4^{-}}\right)$by Scenedesmus obliquus (left) and Chlorella vulgaris (right)

tested were higher than those produced by $C$. vulgaris. Considering all the results, $S$. obliquus cultivated in the Bold medium was found to be the most favorable option for achieving the highest percentage of total lipids.

It is important to note that a relatively simple medium such as the AAP allows both algae $S$. obliquus and C. vulgaris to synthesize desirable amounts of lipids. Although the biomass productivity of S. obliquus was the lowest in the AAP medium, it was not necessarily low for a medium that is designed only to determine if the algae can tolerate certain conditions of growth.

Nitrogen and phosphate are two of the macronutrients that are crucial for cell growth and metabolism. Nitrogen is a critical element in the formation of proteins, lipids, and nucleic acids (Guschina and Harwood, 2013), while phosphate is essential for the synthesis of ATP, phospholipids, and the backbone of DNA and RNA (Andersen, 2013). In our studies, both $S$. obliquus and C. vulgaris showed a complete consumption of nitrogen and a partial consumption of phosphorus in Bold and
Bristol culture media (particularly faster consumption by S. obliquus), which favored a rapid accumulation of lipids (Esakkimuthu et al., 2016; Kiran et al., 2016; Lari et al., 2016). Prasad and coworkers (2018) indicated that the uptake of phosphorus and nitrogen is linked. When the rate of nitrogen consumption is low, phosphorus consumption is affected and substantially reduced (Fig. 3). Similarly, in our study, it was observed that even when nitrogen had been consumed (almost completely), phosphorus continued to be consumed by the cells, but at a reduced rate (Fig. 3). Although the expense of both nutrients in the AAP medium was similar for $S$. obliquus and $C$. vulgaris (Fig. 3A and Fig. 3B), the latter did not accumulate the same amount of lipids, and the amount was significantly lower than that accumulated by $S$. obliquus (Fig. 4). The possible influence of phosphorus on biomass production and lipids synthesis is particularly striking since its concentration in the three media was very different $(53.2 \mathrm{mg} / 1,26.6 \mathrm{mg} / \mathrm{l}$, and $0.2 \mathrm{mg} / 1 \mathrm{in}$ Bold, Bristol, and AAP, respectively) and it was not ex- 


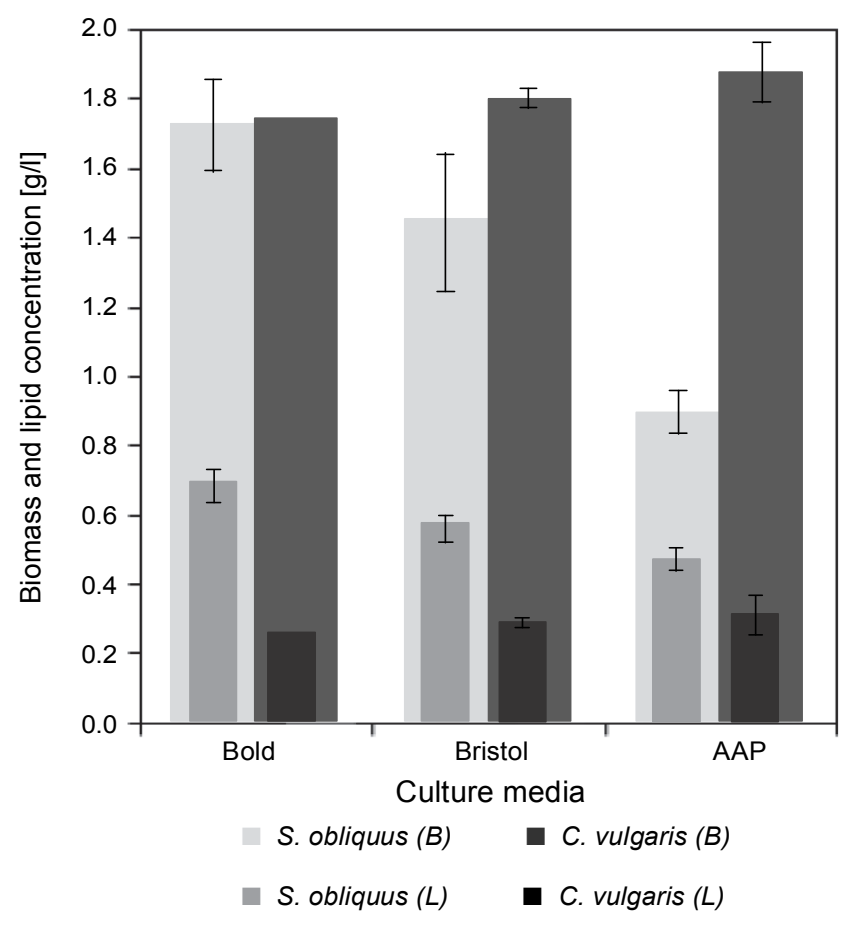

Fig. 4. Concentration of total biomass (g/l) and total lipids (g/l) produced by Scenedesmus obliquus and Chlorella vulgaris

hausted completely. By reducing the phosphorus content in the medium for different algal species including C. vulgaris, Ghafari and coworkers (2018) obtained lower percentages of lipids; however, this behavior depended on the algae studied. In the present work, there was no significant difference observed in the final concentration of lipids produced by $C$. vulgaris $(14.29 \%$, $15.79 \%$, and $16.76 \%(\mathrm{w} / \mathrm{w})$ in Bold, Bristol, and AAP, respectively), but in the case of $S$ obliquus there was a difference in the amount of total lipids depending on the growth medium used $(39.60 \%, 39.18 \%$, and $52.51 \%$ $(\mathrm{w} / \mathrm{w})$ in Bold, Bristol, and AAP, respectively).

Micronutrients play a critical role in the metabolic functions of algae, since these elements present in the media act as co-enzymes or energy carriers (Juneja et al., 2013). A concentration of calcium and magnesium below $50 \mathrm{mg} / \mathrm{l}$ was shown to promote lipid accumulation in S. obliquus, although the biomass concentration was not significantly affected (Esakkimuthu et al., 2016). Similarly, in the present study, the growth of $S$. obliquus in the AAP medium with low concentrations of calcium and magnesium (Table 1) resulted in the highest percentage of lipid accumulation, compared to the percentages obtained with the algae cultured on Bristol and Bold media.
The other species $C$. vulgaris did not show any difference in lipid deposition between the three culture media tested, indicating a possible tolerance to scarcity conditions or a minor requirement for these elements.

Micronutrients such as molybdenum, iron, and manganese have been shown to be important for the assimilation of scarce nitrogen (Glass et al., 2009) for the pathways of lipid synthesis (Li et al., 2014); however, their effect on lipid accumulation is specific in each species (Ghafari et al., 2018). Finally, other elements present in small concentrations (lower than $0.15 \mathrm{mg} / \mathrm{l}$ ) such as zinc (that is only used in the AAP medium) and copper (present in all the media) stimulate algal cell growth but not the accumulation of lipids (Battah et al., 2015; Sibi et al., 2016; Zhu et al., 2016; Hamed et al., 2017; Ghafari et al., 2018).

\section{Conclusions}

Of the two algae evaluated, the highest biomass production was achieved using the AAP medium $(1.880 \mathrm{~g} / \mathrm{l})$ for $C$. vulgaris and Bold medium (1.730 g/l) for S. obliquus. On the other hand, lipid accumulation was stimulated in both algae cultured on AAP medium, with values as high as $52 \%(\mathrm{w} / \mathrm{w})$ in $S$. obliquus and $16 \%(\mathrm{w} / \mathrm{w})$ in C. vulgaris. It can be noted that in the case of $S$. obliquus, the AAP medium favored the accumulation of lipids rather than increase in the amount of biomass; on the other hand, $C$. vulgaris showed increased production of both biomass and lipids on this medium.

Thus, the results obtained in the present study suggest that the biology of each algal species plays an essential role in the assimilation of nitrogen, phosphate, and micronutrients, rather than the biomass production or lipid accumulation.

\section{Acknowledgment}

The authors thank Universidad Francisco de Paula Santander for providing materials and equipment that enabled a successful completion of this research, and the Departamento Administrativo de Ciencia, Tecnología e Innovación COLCIENCIAS, for its Francisco José de Caldas scholarship program to support national $\mathrm{PhD}$ doctorates and its Jóvenes Investigadores program for young research talents.

\section{References}

Andersen R.A., Berges K.A., Harrison P.J., Watanabe M.M. (2005) Appendix A - recipes for freshwater and seawater media. [in:] Algal culturing techniques. Ed. Andersen R.A. Academic Press, Boston USA: 429-538. 
Andersen R.A. (2013) The microalgal cell. [in:] Handbook of microalgal culture: applied phycology and biotechnology Ed. Richmond A., Hu Q. John Wiley \& Sons, West Sussex UK: $3-20$.

APHA (2017) Standard methods for the examination of water and waste water. American Public Health Association, Washington, DC. USA.

ASTM (2012) Standard guide for conducting static toxicity tests with microalgae. E1218-04. [in:] Annual Book of ASTM Standards, vol 11.06, West Conshohocken, PA, USA.

Battah M., El-Ayoty Y., Abomohra A.E.F., El-Ghany S.A., Esmael A. (2015) Effect of $\mathrm{Mn}^{2+}, \mathrm{Co}^{2+}$ and $\mathrm{H}_{2} \mathrm{O}_{2}$ on biomass and lipids of the green microalga Chlorella vulgaris as a potential candidate for biodiesel production. Ann. Microbiol. 65(1): 155-162.

Bohnenberger J.E., Crossetti L.O. (2014) Influence of temperature and nutrient content on lipid production in freshwater microalgae cultures. An. Acad. Brasil. Ciên. 86(3): $1239-1248$.

Carvalho E.M., Ottonelli F., Ansilago M., Godoy H.C., Nakagaki J.M., Ramires I. (2012) Growth kinetics of the microalga Pseudokirchneriella subcapitata (Korshikov) Hindak (Chlorophyceae) in natural water enriched with NPK fertilizer. Biochem. Biotech. Rep. 1(2): 14-18.

Dragone G., Fernandes B.D., Abreu A.P., Vicente A.A., Teixeira J.A. (2011) Nutrient limitation as a strategy for increasing starch accumulation in microalgae. Appl. Energy 88(10): 3331-3335.

Esakkimuthu S., Krishnamurthy V., Govindarajan R., Swaminathan K. (2016) Augmentation and starvation of calcium, magnesium, phosphate on lipid production of Scenedesmus obliquus. Biomass Bioenergy 88: 126-134.

Fazeli Danesh A., Mooij P., Ebrahimi S., Kleerebezem R., van Loosdrecht M. (2018) Effective role of medium supplementation in microalgal lipid accumulation. Biotech. Bioengin. 115(5): 1152-1160.

Ghafari M., Rashidi B., Haznedaroglu B.Z. (2018) Effects of macro and micronutrients on neutral lipid accumulation in oleaginous microalgae. Biofuels 9(2): 147-156.

Glass J.B., Wolfe Simon F., Anbar A.D. (2009) Coevolution of metal availability and nitrogen assimilation in cyanobacteria and algae. Geobiology 7(2): 100-123.

Guschina I.A., Harwood J.L. (2013) Algal lipids and their metabolism. [in:] Algae for biofuels and energy. Ed. Borowitzka M.A., Moheimani N.R. Springer, Dordrecht: 17-36.

Hamed S.M., Zinta G., Klöck G., Asard H., Selim S., AbdElgawad H. (2017) Zinc-induced differential oxidative stress and antioxidant responses in Chlorella sorokiniana and Scenedesmus acuminatus. Ecotoxicol. Environ. Safety 140: 256-263.

Juneja A., Ceballos R., Murthy G. (2013) Effects of environmental factors and nutrient availability on the biochemical composition of algae for biofuels production: a review. Energies 6(9): 4607-4638.
Kiran B., Pathak K., Kumar R., Deshmukh D. (2016) Statistical optimization using central composite design for biomass and lipid productivity of microalga: a step towards enhanced biodiesel production. Ecolog. Eng. 92: 73-81.

Lari Z., Moradi-kheibari N., Ahmadzadeh H., Abrishamchi P., Moheimani N.R., Murry M.A. (2016) Bioprocess engineering of microalgae to optimize lipid production through nutrient management. J. Appl. Phycol. 28(6): 3235-3250.

Li M., Zhu Q., Hu C.W., Chen L., Liu Z.L., Kong Z.M. (2007) Cobalt and manganese stress in the microalga Pavlova viridis (Prymnesiophyceae): Effects on lipid peroxidation and antioxidant enzymes. J. Environ. Sci. 19(11): 1330-1335.

Li Y., Han F., Xu H., Mu J., Chen D., Feng B., Zeng H. (2014) Potential lipid accumulation and growth characteristic of the green alga Chlorella with combination cultivation mode of nitrogen $(N)$ and phosphorus $(P)$. Bioresource Tech. 174: 24-32.

Mandal S., Mallick N. (2009) Microalga Scenedesmus obliquus as a potential source for biodiesel production. Appl. Microbiol. Biotech. 84(2): 281-291.

Mandotra S.K., Kumar P., Suseela M.R., Nayaka S., Ramteke P.W. (2016) Evaluation of fatty acid profile and biodiesel properties of microalga Scenedesmus abundans under the influence of phosphorus, $\mathrm{pH}$ and light intensities. Bioresource Tech. 201: 222-229.

Milano J., Ong H.C., Masjuki H.H., Chong W.T., Lam M.K., Loh P.K., Vellayan V. (2016) Microalgae biofuels as an alternative to fossil fuel for power generation. Renewable Sustain. Energy Rev. 58: 180-197.

Moheimani N.R., Borowitzka M.A., Isdepsky A. (2013) Standard methods for measuring growth of algae and their composition. [in:] Algae for biofuels and energy. Ed. Borowitzka M.A., Moheimani N.R. Springer, Dorcrecht: 265-284).

Prasad M.S.V., Varma A.K., Kumari P., Mondal P. (2018) Production of lipid-containing microalgal biomass and simultaneous removal of nitrate and phosphate from synthetic wastewater. Environ. Tech. 39(5): 669-681.

Rodríguez Gil J.L., Brain R., Baxter L., Ruffell S., McConkey B., Solomon K., Hanson M. (2014) Optimization of culturing conditions for toxicity testing with the alga Oophila sp. (Chlorophyceae), an amphibian endosymbiont. Environ. Toxicol. Chem. 33(11): 2566-2575.

Shin Y.S., Choi H.I., Choi J.W., Lee J.S., Sung Y.J., Sim S.J. (2018) Multilateral approach on enhancing economic viability of lipid production from microalgae: a review. Bioresource Tech. 258: 335-344.

Sibi G., Shetty V., Mokashi K. (2016) Enhanced lipid productivity approaches in microalgae as an alternate for fossil fuels - a review. J. Energy Inst. 89(3): 330-334.

Zhu L.D., Li Z.H., Hiltunen E. (2016) Strategies for lipid production improvement in microalgae as a biodiesel feedstock. BioMed Res. Int. 2016: 1-8. 